\title{
RETROSPECTIVE AUDIT OF THE ACUTE MANAGEMENT OF STROKE IN TWO DISTRICT GENERAL HOSPITALS IN THE UK.
}

\author{
O.O. Faluyi, PhD, J.A. Omodara, MSc, K.H. Tay, M.B.B.S. and K. Muhiddin, PhD, FRCP. \\ Medical Directorate, Derby NHS Hospital Foundation Trust, Derby, UK
}

Correspondence:

Dr. O.O. Faluyi,

Edinburgh Cancer Centre,

Western General Hospital,

Edinburgh EH4 2XU, UK

e-mail: sola.faluyi@luht.scot.nhs.uk

\begin{abstract}
Background: There is some evidence to suggest that the standard of acute medical care provided to patients with cerebrovascular disease is a major determinant of the eventual outcome. Consequently, the Royal College of Physicians (RCP) of London issues periodic guidelines to assist healthcare providers in the management of patients presenting with stroke.

Objective: An audit of the acute management of stroke in two hospitals belonging to the same health care trust in the UK.

Method: Retrospective review of 98 randomly selected case-notes of patients managed for cerebrovascular disease in two acute hospitals in the UK between April and June 2004. The pertinent guidelines of RCP (London) are highlighted while audit targets were set at $70 \%$.

Results: $84 \%$ of patients presenting with cerebrovascular disease had a stroke rather than a TIA, anterior circulation strokes were commonest. All patients with stroke were admitted while those with TIAs were discharged on the same day but most patients with TIA were not followed up by Stroke specialists. Most CT-imaging of the head was done after 24 hours delaying the commencement of anti-platelets for patients with ischaemic stroke or neurosurgical referral for haemorrhagic stroke. Furthermore, there was a low rate of referral for carotid ultrasound in patients with anterior circulation strokes. Anti-platelets and statins were commenced for most patients with ischaemic stroke while diabetes was well controlled in most of them. However, ACE-inhibitors and diuretics such as indapamide were under-utilized for secondary prevention in such patients. Warfarin anti-coagulation was underutilized in patients with ischaemic stroke who had underlying chronic atrial fibrillation. While there was significant multi-disciplinary team input, dysphagia and physiotherapy assessments were delayed. Similarly, occupational therapy input and psychological assesment were omitted from the care of most patients.

Conclusion: Hospital service provision for the management of cerebrovascular disease needs to provide appropriate specialist follow up for patients with TIA, prompt radiological imaging and multi-disciplinary team input for patients with stroke. Furthermore, physicians need to utilize appropriate antihypertensives and anti-coagulation more frequently in the secondary prevention of stroke.
\end{abstract}

Keywords: Stroke, anti-platelets, anti-coagulation, carotid stenosis, secondary prevention

\begin{abstract}
Abbreviations: ACE-inhibitors: angiotensin-converting enzyme inhibitors, AF: atrial fibrillation, CT-head: computerized tomography scan of the head, DCGH: Derby City General Hospital, DRI: Derbyshire Royal Infirmary, HMG-CoA: 3-hydroxy-3-methylglutaryl-coenzyme-A, MRI: magnetic resonance imaging, NHS: National Health Service, RCP: Royal College of Physicians, TIA: transient ischemic attack.
\end{abstract}

\section{INTRODUCTION}

Cerebrovascular disease refers to focal neurological deficit of vascular origin. This spectrum of clinical disorders ranges from a transient ischemic attack (TIA) which lasts less than 24 hours to a stroke which lasts longer than 24 hours. Approximately 150000 cases of stroke are diagnosed annually in the population of England and Wales with 65\% of cases occurring in those over the age of $75^{1}$. Cerebrovascular disease remains a leading cause of morbidity and mortality worldwide particularly among the elderly ${ }^{2}$. Furthermore, strokes remain one of the most common reasons for the acute admission of elderly patients $^{3}$. In a large population-based study of approximately 20000 people in Copenhagen, age, sex, household income, smoking, systolic blood pressure, diabetes mellitus, serum cholesterol, ischaemic heart disease and atrial fibrillation were identified as significant risk factors for stroke ${ }^{4}$. In multi-racial communities, cerebrovascular disease has a higher incidence in the black population ${ }^{5}$. The largest longitudinal study reported in the UK suggests that despite a reduction in the age and gender-specific incidence rates of stroke over the past 25 years and disability from stroke, the overall disease burden has been stable due to the increasing elderly population ${ }^{6}$. This suggests that given the further projected increase in the elderly population over the forthcoming years, more effort needs to be devoted to the effective 
management of cerebrovascular disease to reduce disability and mortality from this condition.

In the management of stroke, treatment given in the acute phase and the secondary preventive measures instituted appear to be the major determinants of outcome $^{7}$. Therefore, the Royal College of Physicians (RCP) of London issues periodic guidelines to assist physicians with the management of stroke ${ }^{8}$. Some of these guidelines specify standards of care recommended in the acute phase. This audit was carried out to determine if the management of patients presenting at two District General Hospitals with emergency services in the UK in 2004 conformed to the RCP guidelines.

\section{MATERIALS AND METHODS}

50 patients managed for cerebrovascular disease at each of the two National Health Service (NHS) Acute Hospitals in Derby - Derby City General Hospital (DCGH) and Derbyshire Royal Infirmary (DRI) between April 1 and June 30, 2004 were randomly selected by a computer of the records department of the hospitals. Case notes for 48 patients were retrieved at DCGH while the case notes for 50 patients were retrieved at DRI. Of the 98 patients, 46 were male, 52 were female (Age range: 46 to 98). Clinical syndromes of stroke were determined based on a physical examination on admission and CT-head findings. An audit pro-forma was designed based on the standards of care recommended by the RCP (London) in 2004 and used for data collection from the case notes by 4 doctors in postgraduate training in medicine ( 2 from each hospital). The data was collated and analyzed at a joint meeting. Audit standards were set at $70 \%$. Where patients died, they were excluded from the analysis. However, as the guidelines and good clinical practice specify that the steps in the management of patients with stroke should be well documented, where there was no documentation to suggest that the stipulated standard of care had been met, the case was treated as if the standard of care had not been met. Ethical approval for the project was sought from the hospital audit committee and the results have been submitted to the same committee.

\section{Summary of RCP Guidelines Relevant to this Study \\ Acute Management}

(1) All patients presenting with a TIA should be followed up by Stroke Specialists (defined by the RCP as a Neurologist or a Geriatric Physician) in a Neurovascular Clinic.

(2) All patients presenting with stroke should be admitted and have a complete neurological examination.

(3) All patients presenting with stroke should have a computerized tomography scan (CT-scan) of the head within 24 hours.

(4) All patients with ischaemic stroke (diagnosed on CT-head) should have additional anti-platelets commenced in the absence of contra-indications.
(5) No patient should receive anti-platelets prior to a CT-head confirmed diagnosis of ischaemic stroke.

(6) All patients with suspected intracranial haemorrhage on CT-head should have an urgent neurosurgical opinion sought.

(7) All diabetic patients with stroke should have their blood glucose levels maintained at less than - 10 mmoll ${ }^{-1}$ while on admission.

\section{Secondary Prevention}

(1) All patients with ischaemic stroke should receive HMG-CoA reductase inhibitors (statins) as soon as possible (where serum cholesterol $>3.5 \mathrm{mmol}$ $\left.1^{-1}\right)$.

(2) All patients with ischaemic stroke should have preadmission anti-hypertensives continued on admission.

(3) In the absence of contra-indications, within two weeks of an ischaemic stroke, all patients should be commenced on an angiotensin-converting enzyme inhibitor (ACE-inhibitor) with or without a thiazide or indapamide.

(4) In the absence of contra-indications, within two weeks of an ischaemic stroke, all patients with chronic atrial fibrillation should be commenced on warfarin anti-coagulation.

(5) All patients with anterior circulation ischaemic stroke should have a Doppler ultrasound scan of the internal carotid arteries and end-arterectomy within two weeks is recommended in the presence of critical internal carotid artery stenosis.

\section{Multi-disciplinary Care}

(1) All patients presenting with stroke should be assessed for dysphagia with a $50 \mathrm{ml}$ water swallow test on admission by an appropriately trained professional.

(2) All patients presenting with stroke should have a dysphasia assessment by a Speech and Language therapist as soon as possible.

(3) All patients admitted with stroke should have a weekly multi-disciplinary team review while on admission.

(4) All patients presenting with stroke should have a physiotherapy assessment within 72 hours of admission.

(5) All patients presenting with stroke should have an occupational therapy assessment prior to discharge to assess for adaptations or equipment required at home for safety after discharge.

(6) All patients should have a psychological assessment within a month of a stroke to check for symptoms of anxiety or depression which could otherwise remain undetected.

\section{RESULTS}

\section{Follow-up of Patients Presenting with TIA}

82 of 98 patients $(83.7 \%)$ were diagnosed with stroke while the rest were diagnosed with TIA. Of patients presenting with TIA, only 38\% were followed up by Stroke Specialists after discharge from the hospital 
upon resolution of their symptoms. The others were followed up by other medical specialists.

The rest of the audit results are on patients presenting with stroke.

\section{Acute Management of Stroke}

Of the 82 patients with stroke, 75 (91.5\%) were diagnosed to have ischaemic stroke following exclusion of haemorrhage on a CT-head scan (Table 1). Cases of haemorrhagic stroke accounted for only $8.3 \%$ of cases with the majority of those being due to anterior fossa haemorrhage (Table 1). Most of the patients with stroke had partial anterior circulations strokes which accounted for $53.7 \%$ of the total number of cases (Table 1). Conformity with RCP guidelines on some relevant aspects of investigation and acute care are summarized in Table 2 . With regards to admissions and the timing of CT-head scans, the entire population of patients presenting with stroke (n $=82$ ) was the reference population. With regards to commencement of anti-platelets, the total number of patients in which haemorrhage was excluded on a CThead scan was the reference population $(n=75)$. With regards to the management of haemorrhagic stroke, the number of patients diagnosed with haemorrhagic stroke on a CT-head scan was the reference population $(\mathrm{n}=7)$. All the patients presenting with stroke were

\begin{tabular}{|c|c|c|}
\hline Clinical syndrome $(\mathrm{N}=82)$ & \multicolumn{2}{|c|}{ Proportion (\%) } \\
\hline Partial anterior circulation stroke & 44 & $(53.7)$ \\
\hline Total anterior circulation stroke & 11 & $(13.4)$ \\
\hline Posterior circulation stroke & 11 & $(13.4)$ \\
\hline Lacunar stroke & 10 & $(12.2)$ \\
\hline Anterior fossa haemorrhage & 6 & $(7.1)$ \\
\hline Posterior fossa haemorrhage & 1 & $(1.2)$ \\
\hline Subarachnoid haemo rrhage & 0 & $(0)$ \\
\hline
\end{tabular}

Table 1: Clinical Syndromes - The proportion of patients presenting with stroke at DCGH and DRI who had the respective clinical syndromes of stroke. Total number of patients admitted with stroke: $\mathrm{N}=82$ (1 patient had combined partial anterior circulation and lacunar features on CT-head).

\begin{tabular}{|c|c|c|}
\hline Audit $P$ arameter & Proportion $(\%)$ & $\begin{array}{l}\text { Number of patients records that were available } \\
\text { for assessment (R) }\end{array}$ \\
\hline Admission to hospital & $82 / 82$ & $\mathrm{R}=82$ (All patien ts presenting with $\mathrm{s}$ tro $\mathrm{ke}$ ) \\
\hline CT-head within 24 hours & $38 / 79$ & $\begin{array}{l}\mathrm{R}=79 \text { ( } 3 \text { died with in } 24 \text { hours before they could } \\
\text { have head scans and were excluded) }\end{array}$ \\
\hline $\begin{array}{l}\text { Anti-platelet the rapy for } \\
\text { ischaemic stroke within } 24 \\
\text { hours }\end{array}$ & $29 / 75$ & $\begin{array}{l}\mathrm{R}=71 \text { (drug charts } \mathrm{m} \text { issing in } 4 \text { included in } \\
\text { analysis\}, haem orrhagic stroke in } 7 \mathrm{who} \text { were } \\
\text { excluded) }\end{array}$ \\
\hline $\begin{array}{l}\text { Anti-platelet the rapy for } \\
\text { ischaemic stroke commenced } \\
\text { after CT-head }\end{array}$ & $59 / 75$ & $\begin{array}{l}\mathrm{R}=68 \text { (Time of head scan not documented in } 3 \\
\text { and } \mathrm{d} \text { rug charts missing in } 4 \text { \{included in analysis\}, } \\
\text { hem orrhagic stroke in } 7 \mathrm{w} \text { ho were excluded) }\end{array}$ \\
\hline $\begin{array}{l}\text { Urgent neurosurgical opinion } \\
\text { for patients with } \\
\text { haem orrhagic stroke on CT- } \\
\text { head }\end{array}$ & $(100)$ & $\begin{array}{l}\mathrm{R}=7 \text { (The no of patients with haem orrhagic stroke } \\
\text { on CT-head) }\end{array}$ \\
\hline
\end{tabular}

Table 2: Emergency Care - Some audit parameters of emergency care for patients presenting with stroke at DCGH and DRI (Audit targets $=70 \%$ ). Total number of patients presenting with stroke: $\mathrm{N}=82$. 
admitted and a neurosurgical opinion was sought for all the patients with haemorrhagic stroke diagnosed on a CT-head scan. In contrast, less than $70 \%$ of patients had a CT-head scan done within 24 hours or anti-platelet therapy commenced for ischaemic stroke within 24 hours (Table 2). Notably, more than 70\% of patients had anti-platelets commenced only after the exclusion of intra-cranial haemorrhage on head CT-scan (Table 2).

\section{Secondary Prevention of Stroke}

The group of patients with ischaemic stroke $(\mathrm{n}=75)$ were the target of medical measures at secondary prevention of stroke. In such patients, with regards to the continuation of anti-hypertensives on admission, the control of blood glucose levels in diabetic patients and treatment with simvastatin, RCP guidelines were adhered to in more than $70 \%$ of patients (Table 3 ). In contrast, as regards the utilization of thiazides/ indapamide and ACE-inhibitors in secondary prevention of ischaemic stroke, RCP guidelines were adhered to in less than $70 \%$ of patients (Table 3 ). Similarly, warfarin prophylaxis against embolism in chronic atrial fibrillation and carotid doppler ultrasound scans to detect critical internal carotid artery stenosis in anterior circulation strokes were done in less than $70 \%$ of patients (Table 3 ).
Multi-disciplinary Care of Patients with Stroke RCP guidelines were adhered to in less than $70 \%$ of the patients in any of the areas of multi-disciplinary care assessed (Table 4). With regards to dysphagia, physiotherapy assessments and weekly MDT meetings, all the patients presenting with stroke except for those that died within a week $(\mathrm{n}=79)$ were the reference population ( 3 patients died within a week and they all died within 24 hours of admission). The reference population for a speech and language therapist's assessment $(n=43)$ were all the patients with stroke and dysphasia. The patients with stroke that were alive on discharge $(\mathrm{n}=68$ ) were the reference group expected to have had an occupational therapist and psychological assessment. However, 2 patients died after they had been assessed by an occupational therapist but prior to discharge from hospital.

\section{DISCUSSION}

This audit project was designed to assess the performance of services for the management of stroke in two hospitals which jointly provide emergency services for a community of half a million people and is probably representative of hospitals of a similar nature in the UK. For simplicity, we have presented the results from both hospitals together as they serve the same population and belong to the same National

\begin{tabular}{|c|c|c|}
\hline Audit Parameter & Proportion $\quad(\%)$ & $\begin{array}{l}\text { Number of patients records that were available } \\
\text { for assessment }(R)\end{array}$ \\
\hline $\begin{array}{l}\text { Continuation of pre-existing } \\
\text { anti-hyperten sives on } \\
\text { admission }\end{array}$ & $62 / 82$ & $\mathrm{R}=82$ (No of patients presenting with stroke) \\
\hline $\begin{array}{l}\text { Control of diabetes mellitus } \\
\left(\text { glucose }<10 \mathrm{mmoll}^{-1}\right) \text { on } \\
\text { admission }\end{array}$ & $(71.7)$ & $\mathrm{R}=14$ ( No of diabetic patients) \\
\hline $\begin{array}{l}\text { On thiazide within two } \\
\text { weeks or after discharge }\end{array}$ & $13 / 62$ & $\begin{array}{l}\mathrm{R}=62(75 \text { patients presented with ischaemic stroke, } \\
13 \text { of them died in-hospital and were excluded })\end{array}$ \\
\hline $\begin{array}{l}\text { On ACEI within two weeks } \\
\text { or after discharge (patients } \\
\text { on other anti-hypertensives } \\
\text { were excluded) }\end{array}$ & $29 / 62$ & $\begin{array}{l}\mathrm{R}=62(75 \text { patients presented with ischaemic stroke, } \\
13 \text { of them died in-hospital and were excluded })\end{array}$ \\
\hline $\begin{array}{l}\text { On simvastatin within two } \\
\text { weeks or after discharge }\end{array}$ & $(74.2)$ & $\begin{array}{l}\mathrm{R}=75 \text { (No of patients with ischaemic stroke, } 13 \text { of } \\
\text { them died in-hospital and were excluded) }\end{array}$ \\
\hline $\begin{array}{l}\text { On warfarin for chronic } \\
\text { atrial fibrillation }(\mathrm{AF})\end{array}$ & $(20.0)$ & $\begin{array}{l}\mathrm{R}=20 \text { (6 patients with AF had contra-indications to } \\
\text { warfarin documented and were excluded) }\end{array}$ \\
\hline $\begin{array}{l}\text { Carotid duplex scan within } 2 \\
\text { weeks for ischaemic anterior } \\
\text { circulation stroke }\end{array}$ & $(13.2)$ & $\begin{array}{l}\mathrm{R}=54 \text { ( } 3 \text { patients who died within } 24 \text { hours were } \\
\text { excluded) }\end{array}$ \\
\hline
\end{tabular}

Table 3: Secondary Prevention - The proportion of patients presenting with stroke at DCGH and DRI who had various secondary preventive measures instituted within two weeks or prior to discharge (Audit targets $=70 \%$ ). Total number of patients presenting with stroke: $\mathrm{N}=82$. 
Health Service (NHS) Trust with common patient management approaches. From these results, it can be seen that the vast majority of patients admitted with cerebrovascular disease presented with stroke rather than a TIA. This may be a reflection of the fact that individuals with short lasting TIAs rather than strokes are less likely to present as acute admissions. Majority of patients with TIAs were not followed up by Stroke specialists as suggested by the guidelines but by other physicians. This situation arose primarily due to the discharge of such patients under the care of the oncall consultant rather than a stroke specialist. Such a trend may affect the quality of care received by such patients as not all other physicians are familiar with current concepts in the management of stroke. Over $90 \%$ of strokes were ischaemic in nature with partial anterior circulation strokes being the commonest. This observations is similar to that of a larger Danish study of over 20000 patients where $89.4 \%$ of strokes were ischaemic ${ }^{9}$. Incidentally, no case of subarachnoid haemorrhage was observed in this study. scans done over 24 hours after admission. It appears as if delayed scans delayed the commencement of anti-platelets in most patients. At the present time, selected patients with ischaemic stroke can be treated with thrombolysis in specialized centres ${ }^{11}$. However, this modality of treatment was not in use in the Trust at the time of the audit. The introduction of thrombolysis in the routine management of stroke in these hospitals would require even more prompt head imaging as a CT or MRI within 3 hours is usually required ${ }^{12}$. Therefore, the timing of head CT-scans is definitely an area for improvement in stroke management in these hospitals. A case can be made for starting anti-platelets prior to a CT of the head on the grounds that the vast majority of strokes are ischaemic. However, this could be detrimental to the patients with haemorrhagic stroke as it could potentially aggravate intra-cranial haemorrhage. A careful analysis of the potential benefits and risks of such an approach is therefore necessary but prompt head CT-scanning would make this unnecessary.

\begin{tabular}{|l|ll|l|}
\hline Audit parameter & Proportion & $\begin{array}{l}\text { Reference subgroup of patients } \\
\text { (R) }\end{array}$ \\
\hline $\begin{array}{l}\text { Dysphagia assessment (by } \\
\text { the water swallow test) on } \\
\text { admission }\end{array}$ & $16 / 79$ & $(20.3)$ & $\begin{array}{l}\mathrm{R}=79 \text { (3 were too drowsy to be } \\
\text { assessed on admission and were } \\
\text { excluded) }\end{array}$ \\
\hline $\begin{array}{l}\text { Physictherapy assessment } \\
\text { (within 72 hours) }\end{array}$ & $28 / 79$ & $(35.4)$ & $\begin{array}{l}\mathrm{R}=79 \text { (3 died within 72 hours and } \\
\text { were excluded) }\end{array}$ \\
\hline $\begin{array}{l}\text { Dysphasia assesment (by } \\
\text { speech and language } \\
\text { therapist) during admission }\end{array}$ & $25 / 43$ & $(58.1)$ & $\begin{array}{l}\mathrm{R}=43 \text { (patients with stroke and } \\
\text { documented dysphasia) }\end{array}$ \\
\hline $\begin{array}{l}\text { Occupational Therapist } \\
\text { assessment prior to discharge }\end{array}$ & $36 / 70$ & $(51.4)$ & $\begin{array}{l}\mathrm{R}=70 \text { (12 died prior to assessment } \\
\text { during admission and were } \\
\text { excluded) }\end{array}$ \\
\hline $\begin{array}{l}\text { Weekly multi-disciplinary } \\
\text { team review on admission }\end{array}$ & $52 / 79$ & $\begin{array}{l}\mathrm{R}=79 \text { (3 died prior to assessment in } \\
\text { a weekly MDT and were excluded) }\end{array}$ \\
\hline $\begin{array}{l}\text { Psychological assessment } \\
\text { within a month or scheduled } \\
\text { after discharge }\end{array}$ & $3 / 68$ & $(65.8)$ & $\begin{array}{l}\mathrm{R}=68 \text { (14 died prior to discharge } \\
\text { and were excluded) }\end{array}$ \\
\hline
\end{tabular}

Table 4: Multi-disciplinary Care - Audit of different aspects of the multi-disciplinary care of patients presenting with stroke at DCGH and DRI. Total number of patients presenting with stroke: N=82.

It was satisfying to note that all patients with stroke were admitted and that anti-platelets were started promptly after the CT-diagnosis of ischaemic stroke in over $70 \%$ of patients. The International Stroke Trial which recruited approximately 20000 patients demonstrated the beneficial effect of aspirin administration within 48 hours in reducing morbidity and mortality from stroke ${ }^{10}$. Similarly, all the patients with a CT-diagnosis of haemorrhagic stroke were discussed with neurosurgeons and anti-platelets were not usually started prior to a CT scan of the head. However, one major shortfall in these hospitals was a delay in CT-head scans with most patients having their
As regards the secondary prevention of stroke, it is noteworthy that over $70 \%$ of patients on antihypertensives had these continued, while diabetes mellitus which was present in 17\% was well controlled on admission and statin therapy was judiciously initiated in ischaemic stroke in over $70 \%$ of patients. On the other hand, despite the results of the PROGRESS study suggesting their benefit in the secondary prevention of ischaemic stroke ${ }^{13}$, ACEinhibitors and diuretics such as indapamide were underutilized in secondary prevention. Furthermore, anticoagulation with warfarin in patients with chronic atrial fibrillation which reduces mortality two and a half fold 
within a year ${ }^{9}$ appears to be largely over looked. Admittedly, for a few patients there were genuine concerns about the risk of falls and intracranial haemorrhage on warfarin, but even after the exclusion of these, anti-coagulation appears not to have been contemplated in many patients. This observation becomes more worrying when we consider that $32 \%$ of the patients presenting with stroke had chronic atrial fibrillation.

Carotid endarterectomies in patients with severe internal carotid artery stenosis $(>70 \%)$ reduces the frequency of recurrence of anterior circulation strokes for over 8 years after the initial event ${ }^{14}$. Very few patients managed in these hospitals had duplex scans within 2 weeks of their stroke which suggests that urgent endarterectomies were not a priority in the management plan. This observation would also be worrying, given that anterior circulation strokes were the most common clinical syndrome and severe carotid artery stenosis was a potentially reversible factor which could predispose to further cereborvascular events. However, there may be genuine concerns over the surgical risk of some patients particularly the older ones ${ }^{15}$, which could discourage physicians from considering endarterectomies. This was not explicitly stated for any of the patients.

Dysphagia is common among patients with stroke with prevalence ranging from 37 to $78 \%$ estimated by different techniques ${ }^{16}$. Prompt assessment of dysphagia would prevent aspiration and malnutrition. The $50 \mathrm{ml}$ water swallow test is accepted as one of the most reliable ways of assessing dysphagia but was underutilized in these hospitals ${ }^{17}$. In a similar manner, the proportion of our patients assessed properly for dysphasia was below audit targets. Furthermore, audit targets were not met for physiotherapist assessment within 72 hours which may affect optimization of residual neurological function. Meta-analyses suggests that patients who have community occupational therapy have improved personal and extended activities of daily living ${ }^{18}$ after discharge. These hospitals utilized occupational therapists inadequately in the rehabilitation of stroke patients. Despite the fact that patients with post-stroke depression have a significantly increased mortality $^{19}$, less than $5 \%$ of our patients had a psychological assessment within a month of having a stroke. This raised the possibility that psychological needs were not adequately catered for. Given that the proportion of patients with stroke who were reviewed at weekly multi-disciplinary team meetings nearly hit audit targets, it appears as if the major problem with multi-disciplinary input was prompt involvement of relevant professionals to assess dysphagia, physiotherapy needs, dysphasia and psychological needs. Stroke Units provide a unique opportunity to centralize the care for stroke patients and may potentially help focus appropriately trained personnel and resources on the care of patients with stroke. To this effect, a stroke unit has been recently introduced in one of the hospitals in which these patients were managed. Further studies within these hospitals and others would assess how the introduction of stroke units and reflection on findings such as those reported here will influence the management of patients presenting with features suggestive of cerebrovascular disease.

\section{CONCLUSION}

Stroke management services should increase the priority of head CT scans and carotid doppler ultrasounds which could significantly influence management. Furthermore, physicians should be encouraged to consider ACEI, diuretics such as indapamide and warfarin in the secondary prevention of ischaemic stroke where indicated. Finally, prompt multi-disciplinary involvement in the assessment and management of stroke patients right from the time of admission should be encouraged.

\section{REFERENCES}

1 Website of the Office for National Statistic of England and Wales: http://www.statistics.gov.uk/ articles/hsq/HSQ12stroke.pdf (last accessed 12 February, 2008).

2 Kleindorfer C., Broderick J, Khuory J, et al., (2006) The unchanging incidence and case-fatality of stroke in the 1990s: a population-based study. Stroke, 37(10): 2473-8.

3 Ogun S.A., Ojini F.I., Ogungbo B., et al., (2005) Stroke in south-west Nigeria: a 10-year review. Stroke, 36(6): 1120-2.

4 Boysen G., Nyobe J., Appleyard M., et al., (1988) Stroke incidence and risk factors in Copenhagen, Denmark. Stroke, 19(11): 1345-53.

5 Kissela B., Schneider A., Kleindorfer D., et al., (2004) Stroke in a biracial population: the excess burden of stroke among blacks. Stroke, 35(2): 426431.

6 Rothwell P.M., Coull A.J., Giles M.F., et. al., (2004) Change in stroke incidence, mortality, case-fatality, severity, and risk factors in Oxofordshire, UK from 1981 to 2004 (Oxford Vascular Study). Lancet, 363(9425): 1925-1933.

7 Zweifler R.M. (2003) Management of acute stroke. South Med Journal, 96(4): 380-385.

8 The website of Royal College of Physicians of London: http://www.rcplondon.ac.uk/pubs/ books/stroke/stroke_guidelines_2ed.pdf (Last accessed 21.03.07.).

9 Andersen K.K. and Olsen T.S. (2007) Reduced post-stroke mortality in patients with stroke and atrial fibrillation treated with anticoagulants: results from a Danish quality-control registry of 22179 patients with ischemic stroke. Stroke, 38(2): 259263. 
10 International Stroke Trial Collaborative Group. (1997) The International Stroke Trial (IST): a randomised trial of aspirin, subcutaneous heparin, both, or neither among 19435 patients with acute ischaemic stroke. Lancet, 349(9065): $1569-1581$.

11 Khaja A.M. and Grotta J.C. (2007) Established treatments for acute ischemic stroke. Lancet, 369(9558): 319-330.

12 Szabo K., Lanczik O. and Hennerici M.G. (2005) Vascular diagnosis and acute stroke: what, when and why not? Cerebrovascular Disease: Suppl 2: 11 18.

13 PROGRESS Collaborative Group (2001) Randomised trial of a perindopril-based blood pressure-lowering regimen among 6105 individuals with previous stroke or transient ischemic attack. Lancet, 358(9287): 10331-1041.

14 Barnett H.J., Taylor D.W., Eliasziw M., et al., (1998) Benefit of carotid endarterectomy in patients with symptomatic moderate or severe stenosis. North American Symptomatic Carotid Endarterectomy Trial Collaborators. New England Journal of Medicine, 339(20): 1415-1425.
15 Miller M.T., Comerota A.J., Tzilinis A. et al., (2005) Carotid endarterectomies in octogenerians: does increased age indicate 'high risk'. Nature Clinical Practice in Cardiovascular Medicine, 2(8): 382 383.

16 Martino R., Foleyl N. and Bohgal S. (2005) Dysphagia after stroke: Incidence, diagnosis and pulmonary complications. Stroke, 36(12): 27562763.

17 Martino R., Pron G. and Diamant N. (2000) Screening for or pharyngeal dysphasia in stroke: insufficient evidence for guidelines. Dysphagia, 15(1): 19-30.

18 Walker MF, Leonardi-Bee J., Bath P et al., (2004) Individual patient data meta-analysis of randomized controlled trials of community occupational therapy for stroke patients. Stroke, 35(9): 2226-2232.

19 Williams L.S., Ghose S.S., Swindle R.W., et al., (2004). Depression and other mental health diagnoses increase mortality risk after ischemic stroke. American Journal of Psychiatry, 161(6): 10901095. 